\title{
Buscando el compromiso: la negociación del Pacto de San Juan de Luz
}

\author{
Luis Carlos Hernando \\ UNED \\ The negotiation of «Pact of San Juan de Luz»
}

\begin{abstract}
RESUMEN
Este trabajo ofrece una visión en detalle del proceso de negociación entre el Partido socialista Obrero Español y la Confederación de Derechas Monárquicas leales a don Juan de Borbón, la cual condujo finalmente a la frágil alianza firmada en el conocido como pacto de San Juan de Luz. El análisis del proceso antedicho, iniciado con el encuentro entre el socialista Prieto y el monárquico Gil Robles en Londres en octubre de 1947 y cerrado en agosto de 1948 en el pueblo francés de San Juan de Luz, sirve para extraer conclusiones sobre el estado objetivo de ambas fuerzas políticas exiliadas, su relación y las causas que llevaron al fracaso de la política de conciliación entre las opuestas fuerzas de

la izquierda y derecha liberal española.
\end{abstract}

PALABRAS CLAVE:

PSOE, Prieto, Monárquicos, Oposición, Exilio, Pacto de San Juan de Luz.

\section{ABSTRACT}

This work offers a view in detail of the process of negotiation between the Socialist Party of Spanish Workers and the Confederation of Spanish Rightists loyal to don Juan de Borbón, which ultimately led to the fragile alliance signed in the so called San Juan de Luz's pact. The analysis of the aforementioned process, initiated with the encounter between the socialist Prieto and the monarchist Gil Robles in London in October of 1947 and closed in august of 1948 in the French village of San Juan de Luz, serves to draw conclusions about the real significance of both exiled political forces, their relationship and the causes that led to the fail of the politics of conciliation between the opposed liberal forces of Spanish right and left.

\section{KEYWORDS:}

PSOE, Prieto, Monarchist, Opposition, Exile, Pact of San Juan de Luz. 


\section{INTRODUCCIÓN}

El presente artículo pretende, a partir de la exposición de una parte del proceso que dio lugar a la firma del pacto de San Juan de Luz, resaltar algunas de las dinámicas existentes en el primer intento de conciliación política entre dos fuerzas antagónicas en la Guerra Civil: el Partido Socialista Obrero Español y la corriente liberal de los seguidores del pretendiente al trono español Don Juan de Borbón. En el momento en el que se produjo, las posibilidades de éxito directo del pacto resultaban escasas, sin embargo resulta interesante su análisis de cara a comprender las relaciones entre fuerzas políticas rivales en el exilio y cómo se concebía la instauración y formación de un régimen postfranquista. Es importante recalcar que nos encontramos frente a un primitivo intento de concertar un periodo de transición política tras la caída de la dictadura.

EI PSOE será, en el exilio, la formación política que con más fuerza abogará por la opción posibilista de cara al futuro de España. Ésta posición coexiste con el proceso de reunificación y cohesión interna del partido, después de las grandes divisiones generadas por el conflicto civil. La figura que liderará ambos procesos será el político bilbaíno Indalecio Prieto, quien, favorecido por la desaparición o descrédito de los demás líderes socialistas, lanzó desde México una ofensiva dirigida a liderar y reunir a las diferentes facciones socialistas (excepto la negrinista) y a impulsar una nueva postura respecto al problema español ${ }^{1}$. Ésta consistió en el convencimiento de que el futuro de España no debía pender de ningún legitimismo previo, desautorizados todos por la Guerra Civil; debía ser resuelta a través de la decisión, mediante consulta directa, del pueblo español. Esta idea, enunciada tan temprano como $1938^{2}$, significará que la ascensión política de Prieto dentro del PSOE quedará vinculada a la separación del partido de las instituciones republicanas formadas en el exilio y a la formación de un frente antifranquista que agrupase al mayor número de fuerzas posible, lo que incluía preferentemente a los monárquicos opuestos a la dictadura. Esta vía ganará apoyos hasta conseguir imponerse en la Asamblea de Delegados Departamentales de 1947, en la cual se forma provisionalmente la Comisión Especial, encargada de organizar la creación de un amplio frente antifranquista lo más abierto posible ${ }^{3}$. No carecerá de oposición, tanto fuera como dentro del PSOE, por parte de quienes consideraban la legitimidad del régimen republicano irrenunciable. Por esto Prieto estará obligado, a lo largo del tedioso proceso de negociación, a presentar ante su partido avances que justifiquen su posición y a intentar evitar los fracasos y retrasos que proveían de argumentos a sus opositores, empeñados en demostrar el error prietista y redirigir al PSOE hacia la posición del legitimismo Republicano.

1 C. TCACH y C. REYEs: Clandestinidad y exilio. Reorganización del sindicato socialista 1939-1953, Madrid, Ed. Pablo Iglesias, 1986, pp. 22 y ss.

2 I. Prieto: Trayectoria de una actitud. 2. a parte, Tlalpan, Fundación Indalecio Prieto, 1996, pp. 176.

3 Ver J. C. GiBAJA VeLÁzQUez: Indalecio Prieto y el socialismo español, Madrid, Pablo Iglesias, 1995, p.389 
La situación de los negociadores monárquicos también resultaba compleja. Los seguidores de don Juan estaban divididos entre los opuestos al régimen franquista y los, en su mayoría residentes en el interior, simpatizantes con la dictadura. Esto hizo que la posición del pretendiente resultase muy sensible a las posibilidades de permanencia del régimen y que en ocasiones se mostrase contradictoria. Desde el fin de la guerra mundial, siguiendo al aislamiento internacional del régimen, la postura monárquica será la de oposición a éste, por lo que su dirección política recaerá en sus seguidores liberales, principalmente Gil Robles y Sainz Rodríguez. Esto no será impedimento para que, según la posición del régimen franquista se consolide, los consejeros interesados en un entendimiento entre el pretendiente y el dictador consigan tomar posiciones y terminar por producir un giro en su política. A pesar de eso el plan de los políticos monárquicos liberales de cara a una negociación con las izquierdas exiliadas quedará definitivamente articulado en julio de 1947. Conocido como «plan C» ${ }^{4}$ consistía en mantener abierta la negociación con las fuerzas políticas de izquierda, principalmente con el PSOE, aunque manteniendo una posición dilatoria a la espera de que su precaria situación deviniese en crítica y les obligase a aceptar de forma incondicional las propuestas monárquicas. Sólo debía presionarse hacia la realización de un acuerdo si la situación internacional se mostraba favorable a la consolidación del franquismo. El objetivo monárquico era crear un régimen basado en la constitución de 1876, rechazando soluciones puramente democráticas tales como un gobierno interino mixto o un plebiscito previo. Una vez obtenido el acuerdo sobre esos puntos se pasaría a negociar desde la unidad política con las potencias, de cara a obtener su apoyo para producir la caída del régimen franquista. Todo esto debería realizarse con la mayor de las discreciones, evitando soliviantar o asustar a los monárquicos franquistas. La restauración monárquica definitiva vendría de manos de un gobierno provisional que, en lugar de cortes, contaría con una asamblea consultiva. La posición monárquica no contemplaba nada más que la final restauración monárquica avalada por su propia legitimidad, sin el concurso previo de la sociedad española.

El principal modulador de la acción política de los exiliados fue el desarrollo de la situación internacional. Los variables intereses ideológicos y estratégicos de las diferentes potencias afectaron grandemente la forma de actuar de los opositores al franquismo, ya fuese por su relego a la irrelevancia internacional, como ocurrió con aquellas soluciones que no eran de su agrado, como la legitimista republicana, o favoreciendo líneas de acción basadas en la unión antifranquista.

La dinámica conductora de las políticas de las potencias respecto al régimen español será, simplificando, la relación entre el idealismo, que consideraba al régimen como un vestigio de las fuerzas derrotadas en la Segunda Guerra Mundial que no tenía lugar en el nuevo orden mundial, y el realismo, impuesto por los in-

4 Respecto a éste ver F. DE MEER, Juan de Borbón. Un hombre sólo, Valladolid, Junta de Castilla y León, 2001, p. 258 y ss. 
tereses económicos y estratégicos de las potencias en la península, que ganaría en peso según creciese la tensión de la guerra fría. De este modo Gran Bretaña, que poseía un gran interés en determinadas materias primas necesarias para su reconstrucción encontradas en circunstancias inmejorables en España y acuciada por la expansión comunista en el mediterráneo, puso desde el principio como condición para una actitud decidida frente a Franco la existencia de una solución moderada que sirviese como sustitutivo ${ }^{5}$. Estados Unidos, en su nuevo papel de superpotencia se encontraba en una situación diferente. Sus intereses económicos en España eran muy bajos y el problema español resultaba secundario frente a otros creados por la situación de posguerra. Esto permitió en un principio una orientación más ideológica de su política. Pese a eso su creciente responsabilidad global hizo que el crecimiento de la tensión de la guerra fría le afectase más profundamente, por lo que a partir de 1947 se decantó paulatinamente por la adopción de la solución más rápida y menos traumática de la cuestión española: el mantenimiento de la situación ${ }^{6}$. El caso francés será mucho más complejo, dada su situación política una vez acabada la guerra. Por un lado el contenido ideológico tendrá gran peso debido al dominio de la política de posguerra por las izquierdas y por el sentimiento tanto de culpa, por su actitud durante la Guerra Civil, como de agradecimiento, por la actuación de los republicanos exiliados durante la Segunda Guerra Mundial. Esto, sin embargo, se veía limitado por la necesidad de mantener un contacto comercial directo con España para asegurar el flujo de materias primas y capital necesario para la reconstrucción francesa ${ }^{7}$.

En los primeros momentos de lo que fue conocido como la cuestión española la solución más aceptable consistía en la formación de un sistema moderado, amplio y plural preparado para sustituir a la dictadura, cosa para la que pocos de los opositores exiliados estaban aún preparados. Este empeño de las potencias tampoco sería realizado con total decisión, ya que la necesidad de contentar el antifranquismo mayoritario de la opinión pública se enfrentaba tanto a la necesidad de mantener abiertos los canales económicos e informativos con España como a mitigar la explotación que desde el régimen se hacía del nacionalismo a raíz de las intervenciones de las potencias. Todo esto hacía que si las acciones de las potencias, unilaterales o a través de la ONU, tenían en algún momento gran impacto ideológico y propagandístico careciesen de real efectividad al no llevar aparejadas medidas económicas que pusiesen en verdadera dificultad al régimen. La más destacada de estas medidas fue la declaración tripartita firmada el 4 de marzo de 1946. En ella Francia, Estados Unidos y Gran Bretaña aseguraban que, mientras perdurase el régimen de Franco, España no quedaría homologada en el concierto internacional y, reafirmándose en la no intervención, pedían un concierto entre las fuerzas políticas moderadas que asegurasen la retirada pacífica del dictador y la creación de un gobierno provisional que permitiese al pueblo español dotarse del

\footnotetext{
5 F. Portero: Franco aislado. La cuestión española (1945-1950), Barcelona, Aguilar, 1989.,p.42

6 F. PORTERO: op.cit., p.53 y ss.

7 F. PORTERo: op.cit., p.137 y ss.
} 
sistema de estado que estimase conveniente ${ }^{8}$. El efecto de la nota marcó claramente lo requerido por las potencias de cara a obtener su apoyo y dio pie al inicio de la búsqueda de un concierto por parte de las organizaciones políticas exiliadas, a pesar de que cada una de ellas la interpretara de forma diferente.

1947 es el año en el que el realismo impuesto por la creciente tensión generada por la guerra fría hace girar la política española de las potencias. Desde el cenit marcado por la Asamblea de las Naciones Unidas de diciembre de 1946 donde se recomienda la retirada de embajadores de España, comienza a hacerse claro que el régimen franquista se estabiliza cada vez más, como demuestra la promulgación de la Ley de Sucesión que expresaba su voluntad de permanencia, y que podía ser menos traumático para el entorno internacional adaptarse a su existencia que intentar derribarlo. Aún quedó espacio para un último intento de crear una solución moderada a la dictadura, como fue el encuentro promocionado por Ernest Bevin entre Indalecio Prieto y Gil Robles en Londres, pero lo que fue entendido por los políticos españoles como un punto de partida marcó para los diplomáticos del bloque occidental el fracaso final del intento de sustitución, dejando como única posibilidad el acomodamiento del régimen franquista en el sistema internacional de la posguerra mundial. Para 1948 las posibilidades de éxito del pacto como modelo a la hora de sustituir al franquismo se habían acabado, pero aún podía jugar un papel en la negación o retraso de las ayudas económicas y reconocimiento del franquismo. A pesar del papel que jugaría el pacto a la hora de coordinar estas acciones el fin llegaría en 1949 cuando el préstamo de la banca privada estadounidense ${ }^{9}$ inauguró la progresiva normalización económica y diplomática del régimen español y la derrota de la oposición al franquismo en el exilio.

\section{PRELIMINARES A LA NEGOCIACIÓN, OCTUBRE-NOVIEMBRE 1947}

Uno de los hitos más destacados por la historiografía ${ }^{10}$ referente al acercamiento entre socialistas y monárquicos señaló la ambigüedad y confusión que siguió todo el proceso. Durante un viaje de Prieto a Londres y tras intentos infructuosos para que ambos líderes se encontrasen, surgió la posibilidad de utilizar la mediación de Foreign Office para organizar la entrevista. Gracias a la presión conjunta de correligionarios y de las embajadas de Francia y Reino Unido Gil Robles se verá obligado, pese a su resistencia, a partir al encuentro del líder socialista. El encuentro se realizó a lo largo de cinco días junto a frecuentes entrevistas con Ernest Bevin por parte de cada uno de los implicados. El saldo de la entrevis-

8 F. PORTERO: op.cit., p.147 y ss.

9 F. PORTERo: op.cit.,p.351 y ss.

10 Las descripciones del encuentro son numerosas, entre ellas: se puede consultar J. C. GIBAJA, op. cit.p. 403 y ss.; J. M. TOQUERo, Franco y don Juan. La oposición monárquica al franquismo, ed. Plaza y Janés, 1989, p. 214 y ss.; F. DE MEER, op.cit.,p. 265 y ss.; entre otros. 
ta lo conocemos gracias al memorando redactado por Prieto para el ministro británico en el que transcribe los puntos de la posición monárquica escritos por Gil Robles y las glosas del socialista a cada uno de ellos ${ }^{11}$. Según el memorando los principales desacuerdos giraron en torno al método para implantar un régimen posfranquista, que para los monárquicos era accesorio y que para Prieto $^{12}$ debía ser el de un gobierno transitorio que, tras la devolución de las libertades básicas, convocase elecciones a través de las que el pueblo se dotaría del tipo de régimen que prefiriese. En el punto que se ocupa de ello, el sexto en la proposición de Gil Robles, confluyen dos de las más graves divergencias. Primera, la voluntad de los monárquicos de aceptar cualquier vía que diese lugar a la caída de Franco, dada la posibilidad de un levantamiento de altos mandos del ejército, la cual Prieto considera inadmisible. Segunda, la negativa monárquica a aceptar unas elecciones previas que pusiesen en peligro o diesen una legitimidad mundana a la monarquía; para los socialistas, quienes ya habían tenido que renunciar a la legitimidad del régimen republicano, la libre elección del régimen por parte del pueblo era un deber. Otro desacuerdo principal será el del camino prefigurado por las potencias en la nota de marzo de 1946. El desencuentro será tal que ambos negociadores tratarán de conseguir una declaración de Bevin que apoyase sus puntos de vista. El triunfo fue para Gil Robles quien mostraró una nota firmada de la mano del funcionario británico ${ }^{13}$ a Prieto en la que lo propuesto por las potencias era definido como una mera guía, quedando la aplicación al arbitrio de las fuerzas contrarias a Franco. Pese a estas discrepancias esenciales Prieto evaluó el encuentro como positivo, existiendo «más coincidencias que discrepancias» ${ }^{14}$ y juzgando que aún quedaba espacio para limar los puntos conflictivos. Gil Robles no realizó un juicio tan optimista, considerando únicamente como positivo que Prieto hubiese dado una imagen mucho más intransigente frente al Foreign Office ${ }^{15}$.

Tras el encuentro de octubre la búsqueda de un acercamiento se vio impedidas por problemas personales de cada uno de los líderes españoles, teniendo Prieto que viajar a México para atender a su hijo y Gil Robles a Lisboa, donde se vería retenido por las dificultades de obtener visado creadas por el gobierno español. A su vez, el miedo que desde España se tenía a un concierto entre las fuerzas de

\footnotetext{
11 El memorando fue pedido por Bevin a Prieto, igual que hizo con Gil Robles. Según Prieto ambos líderes españoles acordaron intercambiárselos pero, si bien Prieto entregó copia del suyo al monárquico, éste no hizo lo mismo, alegando la falta de un escribiente que le realizase la copia. Prieto lo interpreta como fruto de la intención de Gil Robles de no dejar constancia firmada de ningún contacto, cosa que encaja perfectamente con la actitud monárquica. AFIP, Monárquicos 1948, Carpeta 2.Carta de Prieto a De los Ríos fechada el 17 diciembre 1947.

12 Es necesario hacer notar que la negociación de Prieto se hace a título personal, a la espera de una ratificación por la Comisión Especial la cual recibirá con posterioridad el 6 de noviembre de 1947 (AFIP, Monárquicos 1947, Carpeta 2. Carta de Antonio Pérez y Trifón Gómez a Bevin fechada el 19 de octubre de 1947)

13 Archivo Fundación Indalecio Prieto (AFIP), Monárquicos 1947, Carpeta 2. Nota entregada por Gil Robles a Prieto el 19 de octubre de 1947.

14 J. C. GiBAJA, op. cit., p. 406

15 J. M. GIL Robles, La monarquía por la que yo luché, Madrid, Taurus, 1976, p. 242.
} 
oposición se evidenció en la campaña de difamación emprendida por la prensa española, que se centró sobre todo en el líder monárquico. Esto le llevó, además de mantener una agria discusión epistolar con Artajo $^{16}$, a pedir a Prieto que negase todo lo relativo al encuentro londinense ${ }^{17}$, cosa que éste hizo ${ }^{18}$.

\section{REANUDACIÓN DE LOS CONTACTOS, DICIEMBRE 1947- ABRIL 1948}

El alto en la negociación se mantuvo hasta diciembre. En los primeros días de ése mes Prieto recibió una carta de Fernando de los Ríos desde Washington en la que se ofrecía como mediador entre el líder socialista y los monárquicos, situación facilitada por su relación con Vejarano. Félix Vejarano, quien jugó un gran papel en el desarrollo del pacto de San Juan de Luz, era hijo del conde de Nava del Tajo y sobrino de José María Ansaldo, quien también tuvo un papel importante en la oposición monárquica. Él y Prieto se habían conocido personalmente en septiembre de ese mismo año cuando el político bilbaíno se vio obligado a recibirle en París ${ }^{19}$. Durante ese mes Vejarano quedó confirmado como emisario de confianza de Gil Robles y colaboró en la organización del encuentro londinense ${ }^{20}$. A partir de ese momento Prieto y Vejarano desarrollaron una relación cordial sin la cual es muy posible que la firma del pacto entre monárquicos y socialistas nunca se hubiese llevado a cabo.

En su primera misiva De los Ríos informará de la posición optimista e interés en proseguir las negociaciones de su contacto monárquico, lo cual quedará reafirmado mediante carta de Gil Robles en la que se mostraba interesado en que «haya una nueva conversación entre los interlocutores que se vieron en Londres». Esta nueva urgencia de los monárquicos respecto a la realización de contactos entre ambas fuerzas se debía, según lo estipulado por el «Plan C», a la progresiva consolidación del franquismo y a los persistentes rumores, muchos originados desde España, de una pronta ayuda de los Estados Unidos que eliminase el riesgo de una desestabilizadora crisis económica en España ${ }^{21}$. Pese a la disposición de Gil Robles las dificultades materiales para realizar el encuentro habían crecido. Prieto no quería alejarse demasiado del lado de su hijo ${ }^{22}$, quien permanecía en estado crítico, por lo que cruzar el Atlántico quedaba fuera de la

16 AFIP, Monárquicos 1947, Carpeta 2. Correspondencia entre Gil Robles y Artajo, fechada el 29 de octubre de 1947.

17 AFIP, Monárquicos 1947, Carpeta 2. Gil Robles, sin data.

18 AFIP, Monárquicos 1947, Carpeta 2. Nota mía entregada a France presse, fechada el 24 o 25 de octubre de 1947.

19 AFIP, Monárquicos 1947, Carpeta 2. Gil Robles (intervención de Bejarano(sic.)), fechada en septiembre de 1947.

20 J. M. Gil Robles, La monarquía por la que yo luché, Madrid, Taurus, 1976, p. 239.

21 AFIP, Monárquicos 1948, Carpeta 1. Carta enviada por De los Ríos a Prieto fechada el 5 de enero de 1948.

22 AFIP, Monárquicos 1947, Carpeta 2. Carta de Prieto a De los Ríos fechada el 13 de diciembre de 1948. 
cuestión. Por su parte Gil Robles veía factible la salida de Portugal, pero dudaba que el gobierno luso dada la presión desde España le permitiese la vuelta, por lo que no se podía permitir el viaje a menos que se tratase de algo decisivo. Prieto se mostraba dispuesto a un encuentro en Washington pero, a pesar del nuevo cauce abierto, dio rienda suelta a su desconfianza hacia Gil Robles ya que sospechaba que por lo único que pactaría era por una aceptación completa de la monarquía, lo cual bastaba para dar por fracasado cualquier contacto ${ }^{23}$. Esa conclusión era extraída de una nota difundida por el líder derechista en el interior de España a raíz de su discusión con Artajo en la que negaba todo contacto con las izquierdas, la validez de la tripartita y, más importante, daba por imposible toda colaboración monárquica con un gobierno de coalición o con la realización de un plebiscito ${ }^{24}$. $\mathrm{Si}$ bien la nota era claramente para consumo interno, ya que la aceptación de cualquiera de esos puntos habría hecho que las masas adictas al franquismo se apartasen de la solución monárquica, bastó a Prieto para reafirmar su desconfianza en el líder derechista ${ }^{25}$, más todavía cuando su publicación en la prensa republicana sirvió para animar a los detractores de la vía plebiscitaria a dar por fracasado el intento de Prieto ${ }^{26}$.

Tras unos intercambios de correspondencia en los que se tanteaba la posibilidad de una nueva entrevista en Washington y la evolución de pareceres de ambas partes desde octubre, Prieto recibe, el día 5 de enero, una carta de De los Ríos que contiene envíos monárquicos del mes anterio ${ }^{27}$. En ellos los líderes monárquicos ${ }^{28}$, tras referirse a la situación del problema español en términos más tétricos de lo usual y de advertir que las potencias no permitirían ninguna solución que desestabilizase políticamente a España o soliviantase a su población católica, claramente dirigidos a preparar a su interlocutor, presentan un proyecto de pacto ${ }^{29}$. El planteamiento del texto resultaba ser mucho más restrictivo que el del redactado en octubre de forma que dejaba la vía abierta a las intenciones monárquicas aunque mantuviese la posibilidad de otro tipo de soluciones. Esta posición monárquica se debía, probablemente, a la creencia de que la urgencia de Prieto por obtener algo material que presentar ante su partido era crítica durante esos meses. Comenzaba refiriéndose al gobierno provisional que seguiría a la caída de Franco como «Gobierno-Regencia». Éste detentaría durante su interinidad todos los poderes y su labor principal sería el establecimiento de un régimen jurídico. Este «Gobierno-Regencia» estaría conformado por «elementos de centro», término del

23 AFIP, Monárquicos 1947, Carpeta 2. Carta de Prieto a De los Ríos el 17 de diciebre de 1947.

24 AFIP, Monárquicos 1947, Carpeta 2. Nota de Gil Robles distrubuida en el interior, 23 de noviembre de 1947.

25 AFIP, Monárquicos 1947, Carpeta 2. Carta de Prieto a De los Ríos el 17 de diciebre de 1947.

26 AFIP, Monárquicos 1947, Carpeta 2.Carta de Prieto a Trifón Gómez fechada el 10 de diciembre de 1947.

27 AFIP, Monárquicos 1948, Carpeta 1. Carta enviada por De los Ríos a Prieto el 5 de enero de 1948.

28 Según Javier Tusell los redactores monárquicos son Gil Robles y Sainz Rodriguez. J. TuSELL, La oposición democrática al Franquismo, Barcelona, Planeta, 1977, p. 194.

29 Ibid. 
que se excluía a las izquierdas moderadas, las cuales podrían proveer de «algún elemento» al aparato gubernamental. A pesar de esta limitación se explicitaba que no sería «a título simbólico», sino como "garantía». Tras un periodo interino en el que un estatuto provisional guardaría las garantías jurídicas se convocaría una consulta en la que según las circunstancias se sometería a aprobación un texto orgánico o se elegiría un organismo constituyente. Una vez expuesto el proyecto los monárquicos volvían a repetir su advertencia de que cualquier indiscreción podía poner en peligro todo el acercamiento. Como se puede ver la nueva propuesta monárquica dejaba abierto el espacio a una restauración unilateral de la monarquía en la que ellos mismos eran capaces de graduar la capacidad de intervención de las izquierdas, tanto en el gobierno provisional como en el proceso de instauración del nuevo régimen postfranquista. Para Prieto debió significar la confirmación de todos sus recelos respecto a las intenciones monárquicas. No extraña que tras este revés político y la cercana muerte de su hijo Luis ${ }^{30}$ se excusase por el momento de una respuesta amparándose en la ausencia de un mecanógrafo ${ }^{31}$. A los dos días escribió su respuesta a los negociadores monárquicos ${ }^{32}$. En ella, tras minimizar las advertencias de los negociadores monárquicos, rechaza el texto propuesto basándose en tres puntos: Primero, la denominación «Gobierno-Regencia» que considera inadmisible al tratarse de un pronunciamiento a favor de un sistema determinado; segundo, el carácter político del «Gobierno-Regencia» que, en los términos expresados, no daría lugar al necesario equilibrio sino a un gobierno plenamente de derechas; y por último la realización de un referéndum, método ya desacreditado por Franco y. Aún prefiriendo un plebiscito directo, estaba dispuesto tomar en consideración unas elecciones de las que surgiese un organismo constituyente, siempre que éste se viera capacitado para establecer la forma de gobierno.

Pese a la desgracia personal que supuso la muerte de su hijo, Prieto se vio en ese momento con la libertad de viajar a Europa, donde mejor se podría llevar a cabo la misión encomendada a la Comisión Especial del PSOE y acudir al próximo III Congreso del PSOE que se convertiría en crucial para su proyecto.

La evaluación que Prieto hacía del panorama internacional resultaba bastante más optimista que la expresada por los monárquicos en su nota anterior: Las potencias no alterarían fácilmente su política hacia Franco y, en el caso de hacerlo, la que lideraría el cambio sería Francia debido a la reciente derrota de los socialistas y encumbramiento del general De Gaulle ${ }^{33}$. Por todo ello tomaba las advertencias monárquicas por erróneas y suponía que la situación internacional no era tan

30 O. CABezAs: Indalecio Prieto. Socialista y español, Madrid, Algaba eds., 2005, p. 590.

31 AFIP, Monárquicos 1948, Carpeta 1. Carta enviada por Prieto a De los Ríos fechada el 10 de enero de 1948.

32 AFIP, Monárquicos 1948, Carpeta 1. Carta enviada por Prieto a De los Ríos fechada el 12 de enero de 1948.

${ }_{33}$ AFIP, Monárquicos 1948, Carpeta 1. Carta enviada por Prieto a De los Ríos del 15 de enero de 1948. 
preocupante como sus interlocutores querían hacer ver. Sí veía más riesgo, esta vez con mayor acierto, en la posición misma del PSOE. En pocos meses daría lugar el III Congreso del PSOE en el exilio en el que se hacía necesario revalidar el mandato dado a la Comisión Especial de forma provisional por la Asamblea de Delegados de 1947. La lentitud y los desencuentros en los tratos con los monárquicos habían animado a los legitimistas opuestos a Prieto, que comenzaban a tomar posiciones. Si para el Congreso no conseguía nada sustancial que presentar, todo lo conseguido hasta el momento, junto con los esfuerzos de Prieto y su capital político invertido desaparecerían sin más.

Prueba de ésta movilización creciente dentro del PSOE quedó demostrada, o así lo entendió Prieto, cuando fue informado desde Francia de la filtración y posterior publicación en prensa del memorando entregado a Ernest Bevin por Prieto ${ }^{34}$. Tras un tiempo durante el que se intentó conseguir la trascripción del texto publicado, quedó confirmado que el punto séptimo, que no fue incluido en las copias enviadas al partido por petición expresa de Gil Robles, no aparecía ${ }^{35}$, lo que permitió suponer que la filtración surgió de una de las copias realizadas para el PSOE, y que el texto tenía una importante modificación en la que quedaba clara la mala intención de los filtradores ${ }^{36}$. La modificación alteraba por completo el punto sexto propuesto por Gil Robles, de forma que se daba por hecha la restauración de don Juan en el trono español ${ }^{37}$. Prieto cargó desde el principio la culpa sobre la oposición a él dentro del PSOE, centrada principalmente en la agrupación de Túnez ${ }^{38}$ que llevaba tiempo atacando la vía posibilista. Prieto llegó a implicar incluso a Rodolfo Llopis ${ }^{39}$, secretario general del PSOE. La intención de los filtradores era clara: la publicación del memorando provocaría recelos y desconfianzas en los monárquicos, dificultando cualquier tipo de pacto. La interpretación que Trifón Gómez, miembro de la Comisión Especial, hacía del asunto era diferente a la de Prieto,

${ }^{34}$ AFIP, Monárquicos 1948, Carpeta 1. Carta enviada por Sánchez Guerra a Prieto fechada el 12 de enero de 1948 .

35 AFIP, Monárquicos 1948, Carpeta 1.Carta de Prieto a Trifón Gómez fechada el 20 de Enero de 1948.

${ }^{36}$ AFIP, Monárquicos 1948, Carpeta 1. Carta de Prieto al director de Ider Presse fechada el 21 de enero de 1948 .

${ }_{37}$ El punto sexto original («Siendo fundamental el problema de la institución en España de una vida política normal se considera como de importancia secundaria el problema del procedimiento que, para implantarlo, permitan las circunstancias. Sin embargo, ninguna solución se considerará como definitiva hasta que haya sido sometida a la resolución de la voluntad de la nación.») quedaba redactado de la siguiente forma: «Estando considerado como substancial el problema de la instauración en España de una vida política normal, la definición del régimen y el sistema que se emplee para instaurarlo, el que las circunstancias aconsejen, es de importancia secundaria. ESTANDO LA MONARQUÍA ESTRECHAMENTE LIGADA A LAS TRADICIONES POLÍTICAS DEL PUEBLO ESPAÑOL, SERÍA ADOPTADO ESTE RÉGIMEN PARA DEFINIR EL ESTADO ESPAÑOL. No obstante esto, ninguna solución sería considerada como definitiva antes de haber sido ratificada por la voluntad de la nación.". Las mayúsculas y la traducción del francés original son de Prieto según la carta de éste al director de Ider Presse del 21 de enero de 1948 (vid. supra). 1948.

38 AFIP, Monárquicos 1948, Carpeta 1.Carta de Prieto a Trifón Gómez fechada el 19 de febrero de

39 AFIP, Monárquicos 1948, Carpeta 1. Carta enviada por Prieto a De los Ríos fechada el 21 de enero de 1948. 
prefiriendo culpar de la filtración a los servicios secretos franceses ${ }^{40}$ a los que se entregó copia para su envío al interior o bien a la $\mathrm{CNT}^{41}$, a través de una copia entregada por los monárquicos, prefiriendo exculpar a Llopis. Sea como fuere la identidad de quienes filtraron el texto nunca quedó aclarada, lo que no contuvo a Prieto para seguir convencido de la autoría de los cargos socialistas. Además los opositores a la labor de la Comisión Especial, con la iniciativa de Wenceslao Carrillo, iniciarán una campaña de informes directos ${ }^{42}$ por las agrupaciones del PSOE, violentando la reglamentación del partido que estipulaba el uso de memorandos y sin informar al jefe en funciones del partido, Trifón Gómez. Para Prieto este nuevo intento de extender desinformación contra él estará relacionado con la filtración, siendo responsable de ambos la ejecutiva del $\mathrm{PSOE}^{43}$, idea en la que se reafirma al enterarse de que los informantes iban armados con la copia del memorando filtrado. ${ }^{44}$

Los contactos con el delegado monárquico, detenidos desde el 12 de enero debido a los problemas ya mencionados y a una grave enfermedad de De los Ríos, son reanudados por Prieto el 9 de febrero, cuando escribe directamente a Vejarano acuciado por la cercanía del Congreso socialista ${ }^{45}$. Desde ese día hasta el 20 de marzo, cuando Prieto debe partir hacia Europa, los intentos de coordinar un encuentro son continuos aunque inútiles. Los meses siguientes tampoco conocerán ningún avance importante debido en parte a la dedicación de Prieto a los preparativos del Congreso.

A pesar de no realizarse ningún contacto directo, de cara al III Congreso Socialista en el exilio los monárquicos mostraron su interés por mantener el contacto y facilitar a Prieto la resolución del Congreso enviando, por medio de Amado Granell, una nota ${ }^{46}$. En ella se aseguraba que un delegado monárquico se encontraría pronto con el político bilbaíno y que éste podía pedir la prórroga en el Congreso sin problema, ya que la realización de un pacto era segura. A pesar de que ese encuentro previo no se materializó, la nota daba algún apoyo a Prieto a la hora de rendir cuentas a un Congreso al que poco tenía que ofrecer. Éste se iniciará con una gran tensión ${ }^{47}$ el 26 de marzo y Prieto se encontraba frente a los más desta-

\footnotetext{
40 AFIP, Monárquicos 1948, Carpeta 1. Carta enviada por Trifón Gómez a Prieto fechada el 19 de enero de 1948.

41 AFIP, Monárquicos 1948, Carpeta 1. Carta de Trifón Gómez a Prieto fechada el 3 de febrero de 1948.

42 AFIP, Monárquicos 1948, Carpeta 1. Carta enviada por Trifón Gómez a Prieto del 28 de enero de 1948.

43 AFIP, Monárquicos 1948, Carpeta 1.Carta de Prieto a Trifón Gómez fechada el 9 de febrero de 1948.

44 AFIP, Monárquicos 1948, Carpeta 1.Carta de Prieto a Trifón Gómez fechada el 10 de febrero de 1948.

45 AFIP, Monárquicos 1948, Carpeta 1.Carta enviada por Prieto a Vejarano fechada el 9 de febrero de 1948 .

46 AFIP, Monárquicos 1948, Carpeta 1. Nota que me entregó Granell en ele aeropuerto de París...fechada el 19 de marzo de 1948.

47 J. MARTínez CoBo: Intrahistoria del PSOE, Barcelona : Plaza y Janés, 1989, p. 153.
} 
cados caballeristas, como De Francisco o Wenceslao Carrillo entre otros, aunque con la importante ausencia de Luis Araquistáin, quien dio pleno apoyo la vía prietista. A pesar de la tensión inicial, las agrupaciones se mostraron progresivamente a favor de Prieto en su condena a la Ejecutiva, hasta el punto de que las sucesivas críticas terminaron por sobrepasar a sus defensores, obligando a Llopis a asumirlas. Los intentos de los caballeristas por revocar las decisiones de la Asamblea de Delegados del año anterior resultaron infructuosos y no lograron impedir una aplastante mayoría de Prieto. La victoria resultó de tal magnitud que permitió a Prieto mostrarse magnánimo, fundiéndose en un fraternal abrazo con De Francisco, su mayor oponente, y evitando así la emisión un voto particular por parte de sus contrarios ${ }^{48}$. A pesar de su lenta evolución la vía del plebiscito y del acercamiento a los monárquicos quedaba expedita.

\section{LA NEGOCIACIÓN SOBRE EL TEXTO, MAYO-JULIO 1948}

El primer día de mayo Prieto recibió de manos de Juan Antonio Bravo una nueva propuesta monárquica ${ }^{49}$. De su tono se desprendía que los líderes monárquicos habían extraído de lo ocurrido desde febrero la idea de que Prieto se hallaba en una situación aún más apurada, ya que el texto resultaba sorprendentemente similar al redactado el 22 de diciembre del año anterior. De hecho la propuesta era más restrictiva, al quedar la anterior representación en el gobierno provisional de «algún elemento de izquierda moderada» reducida en ese momento a la participación de «observadores de izquierda anticomunista» ${ }^{0}$. En su respuesta, Prieto, después de copiar la respuesta dada en enero por considerarla ajustada al nuevo texto, señalaba que el cambio aclaraba la intención monárquica de evitar toda imparcialidad del gobierno provisional y su pretensión de crear uno a su medida, compuesto únicamente por monárquicos. Lo único positivo que Prieto extrajo de la nueva propuesta era la declaración más decidida del europeismo del nuevo régimen, expresada en su quinto punto. Por lo demás el contenido de la carta hacía preguntarse a Prieto si convenía mantener unos contactos que no conducían a ningún sitio ${ }^{51}$. Tras su agria respuesta Prieto se dispuso a enviar noticia del nuevo contacto a los responsables de exteriores de Francia, Estados Unido y Reino Unido con la clara intención de demostrar que la falta de avance en los contactos se debía a la resistencia monárquica ${ }^{52}$.

48 J. MARTínez CoBo: Intrahistoria del PSOE, Barcelona : Plaza y Janés, 1989, p.157 y 158.

49 Los pormenores del encuentro no resultan claros. Gil Robles señala en su diario (op. cit,p,. 259 )el día 9 de abril que Bravo recibió instrucciones para la futura entrevista y el 10 de mayo que las «conversaciones» de Bravo con Prieto no tuvieron resultado alguno. Estos comentarios resultan extraños si, como afirma Prieto, Bravo carecía de toda potestad para negociar (AFIP, Monárquicos 1948, Carpeta 1. Texto sin título, 2 de mayo de 1948.)

50 AFIP, Monárquicos 1948, Carpeta 1. Texto sin título, 2 de mayo de 1948.

51 AFIP, Monárquicos 1948, Carpeta 1. Texto sin título, 2 de mayo de 1948.

52 AFIP, Monárquicos 1948, Carpeta 1. Carta de Prieto a Bidault del 4 de mayo de 1948 y carta de Bevin a Prieto del 20 de mayo de 1948. 
El ultimátum dado por Prieto hubo de hacer efecto entre los negociadores monárquicos ya que en un tiempo relativamente corto, dos semanas, Prieto recibió un extenso memorando acompañado de una propuesta rescrita totalmente y que prefiguraba lo que con el paso del tiempo sería el pacto definitivo. El memorando, iniciado en un tono contemporizador, terminaba por ser un frío baño de realismo. Así, a pesar de conceder al PSOE su capacidad para influenciar en las potencias mediante los sindicatos, describían un panorama internacional en el que el interés material o estratégico de cada potencia las alejaba cada vez más de la causa antifranquista. Los cambios políticos que se realizaban en la esfera internacional, que permitían suponer la ascensión del conservadurismo en las potencias, harían que el realismo impuesto por la guerra fría aconsejase el mantenimiento de Franco y el abandono de los grupos opositores. También se abarcaban los escenarios posibles que sucederían tras una hipotética caída del general Franco. Ésta podía producirse de tres formas: la renuncia, la deposición por los adictos y la revolución. Todos ellos tenían como fin más que probable al ejército como detentador del poder y árbitro de la formación de un régimen postfranquista. Por todo esto la realización del pacto debía adaptarse a los escenarios posibles si deseaba ser aplicable. Pese a eso, la posibilidad de un pronto fin del franquismo se veía tan lejana que los monárquicos explicitaban el principal objetivo que la negociación debía tener en mente: evitar o retrasar todo lo posible unas ayudas internacionales que cada vez se hacían más probables. Más allá del análisis de la situación sugerían que la entrega de un futuro pacto a las potencias interesadas debería realizarse mediante declaraciones paralelas de cada una de las partes, lo que ayudaría a mitigar el impacto político que una declaración conjunta podría crear en los más radicales de las filas monárquicas. El memorando, a pesar de su tono conciliador, no estaba exento de recriminaciones, aprovechando para acusar a Prieto de mostrarse inflexible, de provocar indirectamente la situación de confinamiento de Gil Robles en Portugal por sus indiscreciones y reafirmándose en la conveniencia de no firmar la correspondencia referida al pacto ${ }^{53}$.

La nueva propuesta de pacto que acompañaba al memorando se alejaba por completo de las dos anteriores, desapareciendo la fórmula del "Gobierno-Regencia» y evitando toda referencia a la composición del gobierno de transición. Sus ocho puntos incluían: la instauración de un régimen jurídico que asegurase los Derechos Humanos y limitase el poder ejecutivo, el mantenimiento del orden público e impedimento de toda represalia, el reconocimiento de la religión católica como preferente a la vez que el respeto a las demás creencias, el reajuste económico, la promulgación de una amnistía política, la eliminación de todo totalitarismo, la preparación de España para su entrada en la unión europea y, por último, en su octavo punto, realizar una consulta que permitiese la elección de un sistema definitivo una vez devueltas las libertades básicas ${ }^{54}$. A Prieto el sentido general del texto le resulta aceptable aunque se apresuró a corregirlo con lo que llamó «sencillas va-

53 AFIP, Monárquicos 1948, Carpeta 1. Memorándum, 15 de mayo de 1948.

54 Ibid. 
riaciones de fórmula». Con éstas, además de variar el orden de los puntos, quedaban modificadas la introducción y el punto octavo, las cuales se convertirían hasta el último momento en los principales puntos de discordia. En la primera situaba espacios a rellenar con los nombres de los signatarios de ambas fuerzas y eliminaba la frase inicial en la que se aceptaba «cualquier circunstancia» que produjese la caída del franquismo que dejaba la puerta abierta a un pronunciamiento. En el octavo punto sustituía «consultar [...] la voluntad de la nación» por la expresión más concisa y cercana a sus intereses "convocar elecciones»" ${ }^{55}$.

Pese al gran avance producido en el texto del pacto su respuesta al memorando fue dura y con un marcado tono polemista que se extendería a los intercambios de ambos interlocutores, intoxicando en gran medida los avances de la negociación. De esta forma negaba las consecuencias de la filtración del memorando del Foreign Office apuntadas por los monárquicos y recriminaba el poco interés de sus interlocutores por propiciar un encuentro personal y su ausencia en el reciente Congreso de la Haya. Respecto a la entrega del pacto rechazaba las declaraciones separadas a favor de la más ortodoxa entrega de un texto conjunto. El efecto del método propuesto por los monárquicos sería mucho menor al reducir la percepción de unidad y además abriría la puerta a nuevos retrasos. Por último, en respuesta a un comentario monárquico sobre los militares que actuaban a favor de Don Juan se abriría un estéril debate destinado a determinar qué grupo político contaba con más apoyo en el interior. El debate no sería rechazado por sus interlocutores monárquicos ${ }^{56}$.

El 31 de mayo Prieto recibirá respuesta de manos de Amado Granell, junto con noticias, que se repetirán durante varios meses sin efecto alguno, de la próxima llegada de un emisario monárquico con instrucciones para negociar ${ }^{57}$. Tras continuar las polémicas abiertas en la carta anterior, los monárquicos entraban directamente en uno de los puntos más conflictivos referentes al futuro pacto: la forma de entrega. Frente a la intención de Prieto de hacer entrega de un texto firmado conjuntamente, los monárquicos se mantenían en la preferencia a hacerla por separado ya que permitiría negar la firma de pacto alguno, argumentaban, negando a Franco una reacción nacionalista con la que consiguiese sumar apoyos en el interior. Además de esto, las modificaciones "de fórmula» de Prieto no eran aceptadas por considerarlas «innecesarias y peligrosas», además de ver en ellas un atraso en las posiciones alcanzadas con la nota del 15 de mayo. No se aceptaban ni el preámbulo ni la reformulación del punto octavo. Del primero ofrecían una nueva redacción en la que no se especificaban los nombres de los signatarios, que suponían una entrega conjunta, e introducía de nuevo la aceptación de cualquier circunstancia por la que se produjese la caída del régimen dictatorial. El punto octavo debía ser dejado tal y como aparecía en el texto original. Por último se

\footnotetext{
55 AFIP, Monárquicos 1948, Carpeta 1. Texto sin título, 25 de mayo de 1948.

56 Ibid.

57 AFIP, Monárquicos 1948, Carpeta 1. Nota final, 31 de mayo de 1948.
} 
proponía la conservación de un estricto secreto hasta que la nota fuese publicada y la creación de un Comité de enlace que permitiese la coordinación de ambas fuerzas políticas ${ }^{58}$.

El memorando monárquico fue respondido por Prieto el 8 de junio con gran dureza, para sorpresa de otros miembros de la Comisión Especial ${ }^{59}$. Acusaba a los negociadores monárquicos de pretender entronizar a don Juan sin recurso a la opinión de los españoles, utilizando como argumento el rechazo de la redacción del punto octavo. El método de elección del nuevo régimen resultaba capital para Prieto y se mostraba dispuesto a aceptar solamente la elección directa o la elección de un organismo constituyente capacitado para decidir60. Para reforzar su imagen de hartazgo comentaró repetidamente a Amado Granell, considerando que el ex militar republicano no dudaría en comentarlo a sus contactos monárquicos ${ }^{61}$, haber «perdido el entusiasmo [e ir] perdiendo el interés» ${ }^{62}$. Tras esto las comunicaciones quedaron detenidas durante más de un mes.

A principios de julio, ante la extrañeza de Prieto, un destacado monárquico a quien conocía por haber coincidido con él como diputado en las Cortes de Alfonso $\mathrm{XIII}^{63}$ se detuvo unos días por Biarritz, pero, a pesar de la espera del líder socialista, no estableció contacto ${ }^{64}$. Irritado por el hecho Prieto se puso en comunicación con Granell, quien aseguró, sin llegar a convencerle, que el monárquico no estaba facultado para negociar ${ }^{65} \mathrm{y}$, tras un intervalo en el que consultó a Estoril, proponía una entrevista para finales de ese mes con Vejarano. Para Prieto no era más que otra dilación hasta que en agosto se presentase el «peso pesado» ${ }^{66}$.

Todas estas contradicciones y dilaciones en el proceso negociador condujeron a Prieto a tantear el terreno en busca de otras fuerzas de derechas españolas dispuestas a negociar, ya fuese con el objetivo de cambiar de interlocutores o con el de forzar a los monárquicos a agilizar el trámite bajo la amenaza de ser ignorados en con un pacto alternativo. Por ello, tras prefigurarlo en un discurso pronunciado en Burdeos ${ }^{67}$, se puso en precario contacto a través de socialistas en el interior, con el ex ministro cedista Giménez Fernández ${ }^{68}$, interesándose por la base políti-

58 AFIP, Monárquicos 1948, Carpeta 1. Memorándum, 31 de mayo de 1948.

59 AFIP, Monárquicos 1948, Carpeta 1. Carta de Trifón Gómez a Prieto 21 de junio de 1948.

60 AFIP, Monárquicos 1948, Carpeta 1. Texto sin data, 8 de junio de 1948.

61 Prieto reconoce ante Trifón el propósito de su confesión en carta del 18 de Junio de 1948 (AFIP, Monárquicos 1948, Carpeta 1)

62 AFIP, Monárquicos 1948, Carpeta 1. Carta de Prieto a Granell, 25 de junio de 1948.

63 Éste personaje, al cual Prieto habían elegido anteriormente entre los contactos ofrecidos por Vejarano era probablemente Francisco Moreno Zulueta, conde de los Andes, quien firmaría el pacto definitivo. (AFIP, Monárquicos 1948, Carpeta 2. Carta Prieto enviada a Granell, 15 de julio y carta de Prieto a Asúa del 17 de julio de 1948.)

64 AFIP, Monárquicos 1948, Carpeta 2. Carta de Prieto a Granell, 5 de julio de 1948.

65 AFIP, Monárquicos 1948, Carpeta 2. Carta escrita por Granell a Prieto, 5 de julio de 1948.

66 AFIP, Monárquicos 1948, Carpeta 2. Carta de Prieto a Granell, 17 de julio de 1948.

67 AFIP, Monárquicos 1948, Carpeta 2. Carta de Fancisco Sabaté a Prieto, 8 de julio de 1948.

68 AFIP, Monárquicos 1948, Carpeta 2. Carta de Prieto sin especificar receptor, 18 de julio de 1948 y Carta de «Jorge» a Prieto del 18 de julio de 1948. 
ca que pudiese movilizar y por su actitud de cara a una negociación. La respuesta de Giménez Fernández no resultó muy alentadora ya que señalaba que, aunque podría mandar enviados fuera de España, los contactos nunca serían con organizaciones sino con personalidades ${ }^{69}$.

El 24 de julio Prieto, según quedó programado, se encontró, a pesar de su mala salud, con Félix Vejarano en Pau. Allí le fue entregado al líder socialista un memorando monárquico redactado el 13 de julio. En él se intentaba responder al anterior ultimátum de Prieto, señalando que una ruptura de las negociaciones significaría un fracaso para ambas fuerzas políticas y una victoria para Franco. Para reforzar su argumento amenazaban con que, tras la eventual caída del régimen español, lo más probable era que sucediesen los propios monárquicos, quienes no se verían obligados a negociar con Prieto $^{70}$. Al día siguiente de recibir la carta respondió Prieto, advirtiendo que de no ser por las declaraciones personales de Vejarano matizando el memorando habría dado toda negociación por termina$\mathrm{da}^{71}$. Para Prieto el memorando resultaba completamente regresivo. El texto puesto sobre la mesa resultaba contrario a la voluntad socialista, ya que ésta aspiraba a obtener un pacto lo más concreto posible que no dejase allanado el camino a una simple restauración. Su respuesta siguió con un tono duro, comparando a los monárquicos con los legitimistas republicanos del gobierno del exilio, igualando su intransigencia y resaltando el posibilismo del PSOE. Pese a esto y con un tono de gran irritación terminaba por mostrarse dispuesto a sacrificar la influencia en las negociaciones de la nota tripartita y a aceptar un sistema de entrega de las declaraciones paralelo ${ }^{72}$.

La dureza de la carta dirigida a los líderes de Estoril quedó del todo contrapesada por una nota separada dirigida a Vejarano en la que, prescindiendo del tono polemista, continúaba con la negociación. En ésta señalaba que el punto más conflictivo era el octavo del texto propuesto. La intención de Prieto era evitar en éste cualquier parte susceptible de interpretación y hacer constar expresamente que la voluntad del pueblo español sería consultada mediante elecciones. Además de esto prefería hacer más explícito el europeísmo del futuro gobierno, como forma de hacerlo más atractivo a las potencias y, por último, se negaba a crear un organismo de enlace antes de haberse firmado el pacto ${ }^{73}$.

\section{ÚLTIMA FASE, AGOSTO DE 1948}

La entrevista realizada en Pau dio lugar al inicio de la fase final de la negociación, la cual se vería marcada por la cercanía de los negociadores, ambos resi-

69 AFIP, Monárquicos 1948, Carpeta 2. Manifestaciones verbales de don Manuel Jímenez Fernandez, 20 de septiembre de 1948.

70 AFIP, Monárquicos 1948, Carpeta 2.Memorándum para entregar, 13 de julio de 1948.

71 AFIP, Monárquicos 1948, Carpeta 2. Texto sin data, 25 de julio de 1948.

72 Ibid

73 AFIP, Monárquicos 1948, Carpeta 2. Carta de Prieto a Vejarano, 25 de julio de 1948. 
dentes en San Juan de Luz; por el agravamiento de la enfermedad de Prieto y por la cercanía de la reunión de las Ejecutivas del PSOE y UGT, propuestas para ese mes aunque abocadas a propicios retrasos ${ }^{74}$. Bajo estos condicionantes el mes de agosto será dedicado a concertar las partes del texto en las que persistía la discordia: el preámbulo y el punto octavo. El día 16 Vejarano realizó una nueva entrega en la que se incluía un memorando fechado el día 9, convertido ya en medio de discusión entre los líderes de cada una de las fuerzas políticas ${ }^{75}$, y un documento redactado por él mismo en el que se exponían las visiones y directrices de Estoril concernientes al proceso negociador. Éste incluía el aviso de la próxima llegada del delegado monárquico que debía ocuparse de la última fase, cambios supuestamente secundarios al preámbulo concertado entre Prieto y Vejarano en Pau y una nueva redacción del punto octavo, en el cual se establecía una consulta a «la nación» para elegir el régimen definitivo sin llegar a determinar su modalidad. La poca concreción de los cambios era justificada con la necesidad de evitar la posible desafección de las derechas más radicales y evitar un encorsetamiento excesivo del nuevo régimen. Por último se daba al negociador monárquico libertad para conceder a Prieto la redacción total del punto séptimo, relativo al internacionalismo y europeismo del nuevo régimen ${ }^{76}$.

Dada la posibilidad de continuar las negociaciones cara a cara, Prieto dio una sucinta respuesta escrita ${ }^{77}$, esperando al encuentro personal planeado para el día $20^{78}$. Finalmente se vio obligado a plasmar su opinión en papel, dado que su mala salud impidió la realización de la cita ${ }^{79}$. En su respuesta consideraba inaceptable el cambio «secundario» que se intentaba introducir en el preámbulo desde Estoril, ya que la sustitución de la expresión «normalidad constitucional» por «normalidad institucional» podía dar lugar a equívocos, toda vez que la normalidad institucional sería la monarquía para un monárquico y la república para un republicano. Tal y como se le ofrecía redactó el punto séptimo, acentuando la voluntad del futuro régimen de integrarse en el bloque occidental y de formar parte del proceso de federación europea. Como es lógico su respuesta se endureció al llegar al punto octavo el cual rechazó por resultar más indeterminado que la redacción anterior. La capacidad ilimitada del gobierno provisional de elegir la modalidad por la que el pueblo se dotaría de un régimen era contraria a la voluntad de Prieto y, según él entendía, podía poner en riesgo incluso el apoyo internacional al nuevo régimen, ya que tanto las potencias occidentales, a través de la nota tripartita, como la ONU, en sus declaraciones, apuntaban al pueblo como determinante absoluto

74 AFIP, Monárquicos 1948, Carpeta 2. Carta enviada por Trifón Gómez a Prieto fechada el 2 de agosto de 1948 .

75 AFIP, Monárquicos 1948, Carpeta 2. Memorándum para entregar, 9 de agosto de 1948.

76 AFIP, Monárquicos 1948, Carpeta 2. Carta señalada como confidencial de Vejarano a Prieto fechada el 16 de agosto de 1948.

77 AFIP, Monárquicos 1948, Carpeta 2. Texto sin data, 17 de agosto de 1948.

78 AFIP, Monárquicos 1948, Carpeta 2. Nota de Vejarano a Prieto fechada como «hoy viernes (20 de agosto de 1948)»

79 AFIP, Monárquicos 1948, Carpeta 2. Carta de Prieto a Vejarano fechada el 21 de agosto de 1948. 
del nuevo régimen. Pese al desencuentro del punto octavo Prieto volvía a aceptar el modelo de entrega paralelo y señalaba la urgencia de llegar a un acuerdo antes de la cercana reunión de la Ejecutiva socialista ${ }^{80}$. El día 24 envió nuevas redacciones de ambas partes del texto. En el preámbulo hacía depender la «normalidad institucional» de la voluntad del pueblo, incluyendo así la expresión monárquica acotada según sus intereses. En el punto octavo eliminaba la parte menos concisa y la sustituía por una mención explícita de las elecciones ${ }^{81}$. El día 27 completó la misiva con otra en la que amenazaba con dar por cancelados los contactos durante la reunión con la Ejecutiva, fechada ahora para el 29 , si no se llegaba a un acuerdo respecto al punto octavo ${ }^{82}$.

En este momento crítico para la negociación llegó la sorpresiva noticia, para socialistas y monárquicos por igual, del reciente encuentro a bordo del yate Azor entre don Juan de Borbón y el general Franco ${ }^{83}$. El día previo a la reunión de la Ejecutiva socialista cundió una gran confusión, sobre todo entre los negociadores monárquicos, quienes se sintieron desautorizados por el pretendiente e ignoraban si habían de proseguir las negociaciones ${ }^{84}$. El 29 se reúne finalmente la Ejecutiva del PSOE en la habitación del hotel de Prieto, dada su mala salud, y, tras ser informada de las negociaciones y habérsele presentado la conformidad de todos los miembros de la Comisión Especial ${ }^{85}$, da su aprobación a la labor de la Comisión Especial ${ }^{86}$. La continuación de las negociaciones fue también aprobada desde Estoril ${ }^{87}$. Esto permitió que el día 30 de agosto Prieto matizara su anterior ultimátum, achacándolo a la necesidad de conocer la opinión de la Ejecutiva, y aceptase una redacción final del pacto que incluía la última propuesta del preámbulo de Prieto y una mención al voto secreto de todos los españoles como medio de elegir el futuro régimen. También se llegaba al acuerdo de constituir un Comité de enlace encargado de determinar el momento en el que debía darse publicidad al pacto ${ }^{88}$.

En su redacción definitiva quedaba incluido un rechazo a «cualesquiera soluciones violentas del problema político" en el preámbulo y en su punto octavo se hacía referencia a una consulta a la nación realizada mediante «voto secreto", la expresión más cercana a un proceso electoral a la que se consiguió llegar. El res-

\footnotetext{
80 AFIP, Monárquicos 1948, Carpeta 2. Exopsición de los puntos contenidos en la carta del emisario monárquico de 16 de agosto de 1948 y respuesta a los mismos. 21 de agosto de 1948.

81 AFIP, Monárquicos 1948, Carpeta 2. Propuesta de redacción definitiva para el preámbulo y el artículo 8, 24 de agosto de 1948.

82 AFIP, Monárquicos 1948, Carpeta 2. Carta enviada por Prieto a Vejarano fechada el 27 de agosto de 1948.

83 F. DE MEER, op.cit.,p. 307 y ss.

${ }^{84}$ F. DE MEER, op.cit.,p. 309.

85 AFIP, Monárquicos 1948, Carpeta 2. Carta de Prieto a Jiménez de Asúa fechada el 28 de agosto de 1948.

86 AFIP, Monárquicos 1948, Carpeta 2. Carta de Prieto a Jiménez de Asúa fechada el 30 de agosto de 1948.

87 F. DE MEER, op.cit.,p. 310.

88 AFIP, Monárquicos 1948, Carpeta 2. Carta de Prieto a Vejarano de Asúa fechada el 30 de agosto de 1948.
} 
to del texto se adecuaba a la reorganización realizada por Prieto en su memorando del 16 de mayo y la redacción del punto séptimo realizada el día 20.

Una vez acordado el texto aún quedaba la entrega del texto del pacto a los gobiernos interesados, labor que conllevó serios retrasos y que se llevó a cabo de forma descoordinada, mediando casi un mes entre la entrega en el exterior por los socialistas y en el interior por los monárquicos. Y, por supuesto, la labor de coordinación del Comité recién creado, la cual no resultó menos accidentada que el proceso expuesto.

\section{CONCLUSIONES}

Como se puede ver a partir de esta sucinta exposición los primeros intentos de encuentro entre ambas fuerzas políticas resultaron difíciles y no exentos de problemas y contradicciones.

La comprensión entre miembros de una generación que había compartido diferentes experiencias durante la República y trincheras enfrentadas durante la guerra se hacía casi imposible. Por ello resulta difícil encontrar algún documento entre estos interlocutores que no terminase por devenir en polémica y recriminaciones por hechos tanto de épocas pasadas como presentes. Esto resulta patente en varias ocasiones cuando, a pesar de estar en presencia de las potencias internacionales a las que se intentaba convencer de su unidad, resultaba difícil dejar de comportarse como rivales. Como ejemplo de esto tenemos el comentario de Gil Robles, ya apuntado, sobre el encuentro de Octubre de 1947 en el que se alegraba de que «la sensación de cerrilismo la [haya] dado Prieto» ${ }^{89}$ o las informaciones puntuales de Prieto de las notas monárquicas más intransigentes a las cancillerías de las potencias interesadas con la intención de dar, precisamente, la sensación contraria ${ }^{90}$. Si el objetivo definido era dar una sensación de unidad de cara a conseguir el apoyo internacional estas rivalidades resultaban del todo contraproducentes. Sin embargo es significativo notar cómo la intervención de un personaje de una generación posterior, sin una intervención importante durante el periodo republicano, como fue Félix Vejarano, no sólo facilitó, sino que probablemente posibilitó el acercamiento entre ambas fuerzas políticas.

Resulta importante señalar que ambas fuerzas políticas operaban a partir de concepciones diferentes e incluso contrapuestas del panorama político tanto español como internacional. Los monárquicos partían de una visión mucho más realista, percibiendo cómo la agenda de las potencias se separaba cada vez más de los objetivos antifranquistas. Por ello su objetivo será cada vez menos el obtener una presión internacional que derribase a Franco y cada vez más el retrasar unos

\footnotetext{
89 Ver nota 14

90 Ver nota 49
} 
préstamos internacionales que asegurarían la pervivencia del régimen internacional. La posición socialista quedaba en gran medida indeterminada ya que, aunque Prieto debía haber llegado a las mismas conclusiones, parecía preferir no asumirlas, dado que eso indicaría la futilidad de todo su empeño. De esta forma solía rechazar el análisis monárquico, prefiriendo uno bastante más optimista aunque respaldado por datos más bien anecdóticos. Este posible caso de autoengaño no era privativo de los socialistas, sino que también ocurría en el campo monárquico cuando, contando con la crisis económica como principal arma a la hora de propiciar la caída del franquismo, ignoraban todas las advertencias de las potencias de que nunca permitirían una crisis que desestabilizase el Mediterráneo ${ }^{91}$.

Por último resulta importante señalar que la mayor parte de las conversaciones versaban en todo momento sobre las medidas a tomar una vez el franquismo hubiese caído y muy pocas veces se referían a la forma en que éste caería. Si bien el plan implícito era que la presión de las potencias, una vez contasen con un sistema moderado sustitutivo, conseguiría derribar a Franco, esto entraba en conflicto con la voluntad, en su mayor parte monárquica, de rechazar cualquier intervención exterior en el problema Español. Por su parte el PSOE rechazaba radicalmente todo medio que implicase violencia, como el golpe de estado o la revolución, pero en ningún momento expresaba cual debía ser la actitud si cualquiera de esas opciones se convertía en un hecho.

En nuestra opinión, pese al meritorio esfuerzo realizado en torno al pacto de San Juan de Luz, la década de los cuarenta era aún un periodo demasiado temprano como para llegar a restañar, incluso en el exilio, la brecha abierta durante la Guerra Civil.

91 AFIP, Monárquicos 1948, Carpeta 1. Carta de Rafael Martínez Nadal a Prieto fechada el 20 de mayo de 1948. 